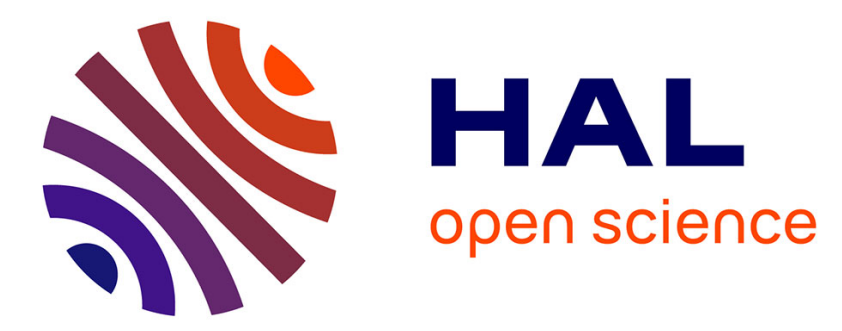

\title{
Factors associated with non-nutritive sucking habits at 2 years of age among very preterm children: EPIPAGE-2 cohort study
}

Sandra Herrera, Véronique Pierrat, Monique Kaminski, Valérie Benhammou, Anne-Laure Bonnet, Pierre-Yves Ancel, Alice Germa

\section{To cite this version:}

Sandra Herrera, Véronique Pierrat, Monique Kaminski, Valérie Benhammou, Anne-Laure Bonnet, et al.. Factors associated with non-nutritive sucking habits at 2 years of age among very preterm children: EPIPAGE-2 cohort study. Paediatric and Perinatal Epidemiology, 2021, 10.1111/ppe.12725 . hal03038662

\section{HAL Id: hal-03038662 \\ https://hal.sorbonne-universite.fr/hal-03038662}

Submitted on 3 Dec 2020

HAL is a multi-disciplinary open access archive for the deposit and dissemination of scientific research documents, whether they are published or not. The documents may come from teaching and research institutions in France or abroad, or from public or private research centers.
L'archive ouverte pluridisciplinaire HAL, est destinée au dépôt et à la diffusion de documents scientifiques de niveau recherche, publiés ou non, émanant des établissements d'enseignement et de recherche français ou étrangers, des laboratoires publics ou privés.

\section{(c)(1)}

Distributed under a Creative Commons Attribution| 4.0 International License 


\section{Factors Associated with Non-Nutritive Sucking Habits at 2 Years of Age among Very Preterm Children: EPIPAGE-2 Cohort Study}

Sandra Herrera ${ }^{1}$, Véronique Pierrat ${ }^{1,2}$, Monique Kaminski ${ }^{1}$, Valérie Benhammou ${ }^{1}$, Anne-Laure Bonnet ${ }^{3,4}$, Pierre-Yves Ancel ${ }^{1,5}$, Alice Germa ${ }^{1,4}$

${ }^{1}$ Université de Paris, CRESS, INSERM, INRA, F-75004 Paris, France

${ }^{2} \mathrm{CHU}$ Lille, Department of Neonatal Medicine, Jeanne de Flandre Hospital, F-59000 Lille, France

${ }^{3}$ Université de Paris, EA2496, F-92120 Montrouge, France

${ }^{4}$ Department of Odontology, AP-HP, Charles Foix Hospital, F-94120, France

${ }^{5}$ Clinical Research Unit, Centre for Clinical Investigation P1419, Cochin Broca Hôtel-Dieu Hospital, Paris, France

\section{Correspondence}

Sandra Herrera, Obstetrical, Perinatal and Pediatric Epidemiology Team, INSERM U1153, Hôpital Tenon, Bâtiment recherche, Paris, France.

Email: sandra.herrera@inserm.fr 


\section{Social media quote}

This is a French study of non-nutritive sucking habits among very preterm children at age 2 years and their association with familial, social, cultural background, health condition during neonatal hospitalization and specified developmental care practices. 


\section{Synopsis}

\section{Study question}

Very preterm children have not achieved maturation of sucking reflexes in utero, and pacifiers are widely used in neonatal units to enhance sucking abilities. Therefore, very preterm children are probably more prone to have non-nutritive sucking habits (NNSHs). This study aimed to identify factors associated with NNSHs among very preterm children.

\section{What's already known}

Prolonged NNSHs have been associated with maxillofacial growth anomalies in the general population; factors associated with NNSHs include maternal age, maternal country of birth, child sex and duration of breast feeding.

\section{What this study adds}

NNSHs in very preterm children at age 2 years were more frequent among girls, children born in multiple pregnancies (e.g., twins/triplets), children fed by nasogastric tube and those who benefitted from development care programs. 


\section{Abstract}

Background: The association between prolonged non-nutritive sucking habits (NNSHs, i.e., sucking pacifiers or fingers) and maxillofacial growth anomalies in the general population has been widely described. Because maturation of sucking abilities is not fully achieved in very preterm infants (<32 weeks' gestation), neonatal services worldwide rely on the use of pacifiers to promote the development of adequate sucking reflexes, possibly prolonging NNSHs during infancy.

Objective: We aimed to describe the frequency and to identify factors associated with NNSHs at age 2 years in very preterm children.

Methods: The study was based on data from EPIPAGE-2, a French national prospective cohort study of preterm births during 2011 that included 2593 children born between 24 and 31 weeks' gestation. The primary outcome was NNSHs at 2 years. Multivariable loglinear regression models with generalized estimation equations were used to study the association between the characteristics studied and NNSHs. Multiple imputations were used to take into account missing data.

Results: The frequency of NNSHs was $69 \%$ in the overall sample but higher among girls (adjusted risk ratio $[R R] 1.12,95 \%$ confidence interval $[\mathrm{Cl}] 1.05,1.17$ ), children born from multiple pregnancies (e.g., twins/triplets) (aRR 1.07, 95\% Cl 1.00, 1.11), children who were fed by nasogastric tube (aRR 1.07, 95\% Cl 1.01, 1.13) or those who benefitted from developmental care programs (aRR 1.10, 95\% Cl 1.02, 1.19). The NNSHs frequency was lower 
if mothers were not born in France (aRR 0.70, 95\% Cl 0.64, 0.77), children had 2 or more older siblings (aRR $0.88,95 \% \mathrm{Cl} 0.82,0.96$ ) or children were breast-fed at discharge (aRR $0.90,95 \% \mathrm{Cl} 0.85,0.95)$.

Conclusions: NNSHs at 2 years seemed associated with cultural background, development care programs and breast feeding. Whether NNSHs at 2 years among very preterm children are associated with future maxillofacial growth anomalies deserves further attention. 


\section{KEY WORDS}

"Very preterm"; "non-nutritive sucking habits"; pacifier; "neonatal care"; "maxillofacial anomalies"; "cohort study". 


\section{BACKGROUND}

Non-nutritive sucking habits (NNSHs) refer to the practice of sucking (e.g., by using fingers or pacifiers) for purposes other than nutrition, especially as an auto-tranquilizing mechanism. ${ }^{1,2}$ NNSHs practiced with a finger is classified as a newborn action in which the finger, usually the thumb, is inserted into the mouth on the middle part of the tongue, exerting pressure on the palate. NNSHs can be practiced with a pacifier ${ }^{3}$ or any other object imitating the shape of a nipple.

Several studies of full-term children have revealed that prolonged NNSHs (longer than 3 years) are associated with a higher risk of maxillofacial anomalies including altered palatal morphology and posterior crossbite (maxillofacial growth anomalies). ${ }^{4-8}$ Prolonged NNSHs are often set at 3 years. However, in a study from the United Kingdom, NNSHs at age 2 years was already found associated with a higher risk of subsequent maxillofacial anomalies. ${ }^{9}$ Factors associated with a higher frequency of NNSHs among the general population have been described in studies from the United Kingdom, Australia and Brazil ${ }^{10-13}$ and included low maternal age, maternal country of birth, high maternal education, female sex, very low birthweight and short periods of breast feeding.

The sucking reflex is acquired in utero between 8 and 18 weeks' gestation (WG). ${ }^{14}$ After 28 WG, the sucking function becomes more complex, especially with the development of the essential sucking-swallowing cycle, which continues to evolve until birth. ${ }^{15,16}$ Among preterm neonates, the harmonious integration of this cycle (together with the breathing cycle) remains immature and uncoordinated ${ }^{17}$; thus, preterm infants may not be able to feed independently. An immature pattern of this physiological function is more marked in 
extremely preterm children ${ }^{18}$; accordingly, the use of a pacifier in neonatal units is recommended to reinforce sucking reflexes and support the maturation of oral neuro-motor activities. ${ }^{19,20}$ Pacifiers are also used for analgesic purposes because non-nutritive sucking (NNS) conditions infants for potentially painful medical procedures and reduces acute pain. ${ }^{21,22}$ Whether this specific use of pacifiers in neonatal units has a role in further NNSHs is unknown.

Since their sucking function is still immature at birth and because NNSHs are widely encouraged in neonatal units, very preterm children are exposed to NNSHs in an uncharacteristic way. On the one hand, very preterm children are different with respect to NNSHs; on the other, prolonged NNSHs are a risk factor for later maxillofacial anomalies. Therefore, prior to studying the links between NNSHs and maxillofacial growth anomalies among very preterm children it was relevant to study the factors associated with prolonged NNSHs among this population.

The objectives of this exploratory study were first to describe the frequency of NNSHs at 2 years' corrected age (CA) and second to identify associated factors, including maternal, social and perinatal characteristics and infant health conditions and care practices, with data collected from a large cohort of very preterm children. 


\section{METHODS}

\section{Cohort selection}

EPIPAGE-2 is a nationwide population-based cohort study in France designed to assess the health and development of preterm children born during 2011. In total, 21 of the 22 metropolitan regions and all 4 overseas regions participated; only one region, representing $2 \%$ of births in France in 2011, did not participate. The detailed protocol has been published elsewhere. ${ }^{23}$ The recruitment period varied by gestational age: 8 months for children born at 22 to 26 WG and 6 months for those born at 27 to 31 WG. Survivors were enrolled for follow-up and were included in the study if their parents consented.

\section{Data collection}

Perinatal, maternal and neonatal data were collected from medical records by local obstetric and neonatal teams in both maternity and neonatology units. Maternal data included demographic and social information and delivery data. Neonatal data included the infant's condition at birth, neonatal complications and care received in neonatal intensive care units. Information related to family circumstances as well as child health and development at 2 years' CA was collected by using a self-administered questionnaire completed by the parents. The questionnaire was sent by post for completion manually or accessed online for completion through secure servers. 


\section{Exposure}

In this exploratory study, we investigated various factors including maternal, social and perinatal characteristics as well as neonatal health conditions and care practices. The variables were selected a priori, first selecting factors associated with NNSHs among the general population in related literature and included maternal age; maternal country of birth; parity $(0,1$ and $\geq 2)$; parents' socioeconomic status defined as the highest occupational status (e.g., professional, intermediate, administrative or public service or self-employed or students, shop assistants or service workers, manual workers and unknown occupation) of the parents or the mother alone if no father was present ${ }^{23}$; child sex; small-for-gestationalage defined as birthweight less than the 10th percentile according to gestational age and sex based on French EPOPé intrauterine growth curves ${ }^{24}$; and breast feeding at discharge.

Second, we selected factors specific to preterm infants susceptible to be associated with NNSHs: gestational age defined as the best obstetric estimate, combining the last menstrual period and the first-trimester ultrasonography assessment; type of pregnancy (single or multiple: twins/triplets); severe neonatal morbidities; feeding by nasogastric tube at 36 weeks' CA; care practices in neonatal intensive care units (Newborn Individualized Developmental Care and Assessment Program [NIDCAP, Appendix, Note 1] or Sensory-motor Developmental Care Programs ${ }^{25-28}$ and Oral Stimulation).

Severe neonatal morbidities ${ }^{23}$ included severe bronchopulmonary dysplasia, severe necrotising enterocolitis, severe retinopathy or severe cerebral abnormalities defined as cranial intraventricular haemorrhage grade III/IV or cystic periventricular leukomalacia (definitions in Note 2 of the Appendix). 


\section{Outcome}

The primary outcome was NNSHs (No/Yes) at 2 years' CA. Three questions relating to NNSHs were included in the questionnaire completed by the parents: Does the child suck his or her thumb; Does the child suck his or her fingers; and, Does the child suck a pacifier? The possible answers to each question were "never", "sometimes", "often" and "all the time or almost". When the answer was "never" to all 3 questions, children were considered not to have NNSHs. When the answer was "sometimes", "often" or "all the time or almost" to one of the 3 questions, children were considered to have NNSHs.

\section{Statistical analysis}

\section{Missing data}

Multiple imputations by chained equations was used to correct for both loss to follow-up and missing data for the outcome (NNSHs) and others variables. ${ }^{29-31}$ For the outcome variable, $20 \%$ of data were missing. For other co-variables, missing data were minimal $(<1 \%)$ for perinatal factors (gestational age, small-for gestational-age and parity) and between 3 and $11 \%$ for neonatal care factors (NIDCAP, oral stimulation and feeding by nasogastric tube). In total, 50 independent imputed datasets were generated. Estimates were pooled according to Rubin's rule..$^{32}$ Imputation details are in eTable 1.

Perinatal and sociodemographic characteristics of the population studied, of those lost to follow-up and of those with missing data on the outcome were described. The distribution of NNSHs was described according to all studied factors. All percentages and crude risk ratios 
(RRs) were weighted to account for differences in the sampling process between gestational age groups. We drew a directed acyclic graph (DAG) that shows the factors selected for study as potential risk factors and as well as their interdependencies (eFigure 1). The adjusted analysis was performed in 3 steps to identify the factors associated with NNSHs using multivariable log-linear regression models. First, model 1 aimed to identify antenatal factors (i.e., maternal age, maternal country of birth, parity, type of pregnancy, parents' socioeconomic status and child sex) related to NNSHs. Secondly, model 2 analysed characteristics at birth (i.e., gestational age and small-for-gestational-age) in relation with NNSHs, adjusting for the factors studied in model 1. Finally, the association of factors related to health status during hospitalization and developmental care practices (i.e., feeding by nasogastric tube, NIDCAP or sensory-motor developmental care and oral stimulation), and the role of breast feeding at discharge with NNSHs were studied in model 3, adjusting for the factors studied in models 1 and 2. Because severe neonatal morbidities are too closely linked to feeding by nasogastric tube at 36 weeks' CA, they were not included in model 3 . Also, because twins (or triplets) share family characteristics and environment and thus do not represent independent observations, generalized estimation equations were used to take into account intra-family correlations. ${ }^{33}$ Results are reported as adjusted RRs (aRRs) with 95\% confidence intervals (95\% Cls).

\section{Sensitivity analyses}

A sensitivity analysis was performed on complete cases. Data were analysed with $R$ v3.5.0.34 


\section{Ethics approval}

Recruitment and data collection occurred only after families agreed to participate. The EPIPAGE-2 study was approved by the French Data Protection Authority (Commission Nationale de l'informatiques et des Libertés no. 911009) and the two relevant ethics committees [the Consultative Committee on the Treatment of Information on Personal Health Data for Research Purposes [CCTIRS], no. 10.626 and the Committee for the Protection of People Participating in Biomedical Research [CPP], no. SC-2873].

\section{RESULTS}

\section{Study population}

Of the 3253 children who survived to 2 years' CA, the parental questionnaire was completed for 2737, 2593 of whom had complete data regarding NNSHs questions. In total, 516 children were considered lost to follow-up, i.e., the parents refused to participate or did not complete the parental questionnaire at 2 years' CA (Figure 1).

As compared with the children included, those lost to follow-up were more often 1) born to younger mothers or who had 2 or more older children (parity $\geq 2$ ); 2) born in single births (not twins/triplets); and 3) born to parents with low socioeconomic status. Children with missing data on NNSHs were more often 1 ) boys; 2 ) born to mothers born outside of France or 3) to parents with low socioeconomic status. In both groups children were less frequently fed by nasogastric tube at 36 weeks' CA (eTable 2). 


\section{Outcome}

Among the 2593 children with available information, 1800 (69\%, 95\% Cl 68-71) had NNSHs at 2 years' CA. After multiple imputation, the frequency of NNSHs was $69 \%$ ( $95 \% \mathrm{Cl} 67-70$ ). Among children with NNSHs: $86 \%$ used a pacifier, $13 \%$ a thumb or fingers and $1 \%$ a combination of pacifiers, thumb and fingers. Among children using a pacifier $78 \%$ of parents responded that their children sucked "often" and "all the time or almost". In cases involving those who use their thumbs and fingers, $38 \%$ of parents responded "often" and "all the time or almost". The frequency of NNSHs according to the studied factors is reported in Table 1.

\section{Factors associated with NNSHs}

Table 2 presents multivariable models estimated by generalized estimation equations with multiple imputations. The frequency of NNSHs was higher for girls (aRR 1.12, 95\% Cl 1.05, 1.17-model 1), children born from multiple pregnancies (e.g., twins/triplets) (aRR 1.07, 95\% $\mathrm{Cl} 1.00$, 1.11-model 1), children who were fed by nasogastric tube at 36 weeks' CA (aRR 1.07, 95\% Cl 1.01, 1.13-model 3) and children who benefited from NIDCAP or Sensory-motor Development Care Programs (aRR 1.10, 95\% Cl 1.02, 1.19-model 3). NNSHs were less frequent if mothers were not born in France (aRR $0.70,95 \% \mathrm{Cl} 0.64,0.77$-model 1 ), if the child had 2 or more older siblings (aRR $0.88,95 \% \mathrm{Cl} 0.82,0.96$-model 1 ) and if the child was breast-fed at discharge (aRR 0.90, 95\% Cl 0.85, 0.95-model 3). Oral stimulation was not associated with NNSHs at 2 years' CA. 


\section{Sensitivity analyses}

Results of the analysis with completed cases provided aRRs very similar to those of analyses based on imputed data (eTable 3).

\section{COMMENT}

\section{Principal findings}

This study revealed a $69 \%$ frequency of NNSHs at 2 years' CA among very preterm children. The frequency was higher among girls, if mothers were born in France and if children were not breast-fed at discharge but was lower if there were older siblings, all in agreement with related literature involving the general population. Our study also revealed that NNSHs were more common among children from multiple pregnancies (twins/triplets), children who were fed by nasogastric tube at 36 weeks' CA and those who benefitted from developmental care programs (NIDCAP or Sensory-motor Development Care).

\section{Strengths of the study}

The EPIPAGE-2 cohort allowed for simultaneous analysis of maternal, social and perinatal characteristics, infant health conditions and care practices specific to very preterm children. Neonatal data (including breast feeding at discharge) were collected prospectively, thus avoiding recall bias. The study's population-based design and large sample size provided reasonable precision in estimating frequencies and associations. 


\section{Limitations of the data}

In total, 660 children were missing (lost to follow-up and with missing data on the outcome). Their characteristics differed from those of children included and were associated with a lower frequency of NNSHs; because children lost to follow-up were probably less prone to have NNSHs, the frequency may have been slightly overestimated. However, the estimated frequency of NNSHs by imputations and in complete cases was the same. The associations found between the studied factors and NNSHs were also similar in the two analyses.

We used a binary outcome variable, NNSHs (No/Yes), based on three questions referring to sucking a thumb, finger or pacifier. In our study, among children who were considered to have NNSHs, $86 \%$ used pacifiers and $13 \%$ thumbs and fingers. Among children who used a pacifier, $78 \%$ of parents responded to the modalities concerning frequency "often" or "all the time or almost", and in cases involving those who used the thumbs and fingers, $38 \%$ of parents responded "often" and "all the time or almost". While the difference between "often" and "all the time or almost" is probably very subjective since the concept "often" is vague, most children who practiced NNSHs were not occasionally suckers, therefore, we are confident in the binary nature of our outcome.

\section{Interpretation}

\section{Frequency of NNSHs}

The frequency of NNSHs observed in the limited existing literature was influenced by the age of the children involved and by cultural similarities and differences among the studied 
populations. Comparing studies with wide age differences ( 7 months to 6 years) is problematic given the natural changes in habits during childhood. Moreover, all studies except one were performed in the general population. Our study observed a NNSHs frequency of $69 \%$ at 2 years' CA among children born preterm, whereas in Australia, the frequency was $79 \%$ among full-term children aged 7 months $(N=670)^{11}$ and in the United Kingdom, 51\% among full-term children aged 24 months ( $N=867) .{ }^{9}$ In a study in Senegal, the frequency of NNSHs was $33 \%$ based on 443 children at age 5 to 6 years, ${ }^{35}$. whereas in China, it was $12 \%$ based on 734 children at age 3 years. ${ }^{36}$ Apart from differences in age, these figures imply cultural differences in the frequency of NNSHs. Although comparing populations as different as those in Senegal, China and France regarding NNSHs is difficult, a recent, albeit limited, Brazilian study conducted in a single municipality (250 children age 3 to 5 years), compared full-term children and preterm children, finding a $54 \%$ frequency of NNSHs in full-term children but $80 \%$ in preterm children. ${ }^{37}$ This result is consistent with ours even though the children in our study were somewhat younger (age 2). Although the Brazilian study was limited in sample size and geographical coverage, the findings suggests that the NNSHs frequency may be higher in preterm than full-term infants.

\section{Family factors associated with NNSHs}

In both France and Australia, countries geographically distant but in some ways more similar culturally than some other areas mentioned above, the NNSHs frequency was lower if the mother was born abroad. ${ }^{11}$ Such results support the idea that sociocultural and family life customs affect NNSHs. Contrary to our initial hypothesis, we found no strong association between parental socioeconomic status and NNSHs. Maternal country of birth and 
socioeconomic status are usually closely linked. Our results suggest that there is no association between socioeconomic status and NNSHs, after adjustment on maternal country of birth.

We sought to study the impact of family size by exploring parity (number of older siblings) and multiple pregnancies (single vs twins/triplets). NNSHs were less frequent among children with 2 or more older siblings but more frequent among children born as a twin/triplet. Among twins, a higher frequency of NNSHs might be explained by a greater need for self-reassurance because, having to simultaneously care for two children of the same age, parents may have reduced time available to concentrate on each child. Furthermore, many multiple pregnancies are due to infertility treatment. Parenting attitudes are likely to differ among mothers with infertility treatment (often older and with higher education) and among those who are multiparous (often with a different cultural environment). These differences may explain why associations between NNSHs and older siblings or multiple pregnancies were in opposite directions.

\section{Children characteristics associated with NNSHs}

In our study, as in others, NNSHs were more frequent among girls than boys. ${ }^{10,12}$ A Swedish study comparing NNS patterns in preterm children revealed a higher sucking rate and higher sucking amplitudes in girls than boys. ${ }^{38}$ These observations agree with other studies suggesting that female children experience greater oral activity than boys, possibly because specific lingual structures and oral and lingual movements develop earlier in girls than boys. ${ }^{39,40}$ 
We also observed a higher frequency of NNSHs for children who were fed by nasogastric tube. Because the maturation of sucking abilities is not fully achieved in very preterm infants, neonatal units favour NNS for stimulating and developing the sucking reflex. This activity is essential to allow such children to feed normally and very important for the maturation of neuro-motor activity. ${ }^{19,20,41,42}$ As expected, our study found higher NNSHs frequency at 2 years' CA among children who benefited from NIDCAP or Sensory-motor Developmental Care Programs; both include NNS to promote the development of oral function and alleviation of pain, although not always with pacifiers. Unexpectedly, we found no association between oral stimulation and NNSHs. Oral stimulation involves perioral and intraoral stimulation but not necessarily the use of a pacifier, which may explain the lack of association between oral stimulation and NNSHs.

Regarding breast feeding, NNSHs were less common among children who were breast-fed at the time of hospital discharge. This finding agrees with the literature: several authors observed an association between longer duration of breast feeding and less use of pacifiers. ${ }^{11,13,37,43}$ In addition, we found no association between NNSHs and factors such as gestational age and small-for-gestational-age.

\section{Perspectives pertaining to maxillofacial growth anomalies}

Several studies of full-term children have shown regular NNSHs for more than 3 years associated with maxillofacial growth anomalies including altered palatal morphology and posterior crossbite. However, because development of the sucking reflex is different in preterm and full-term infants, especially very preterm children, the mechanisms that lead to anomalies of maxillofacial growth might differ. 
According to the few available studies, preterm infants seem at higher risk of maxillofacial growth anomalies than full-term infants. ${ }^{44}$ One study of very preterm children based on data from the EPIPAGE cohort study ${ }^{45}$ observed that altered palatal morphology at 5 age years was more frequent in boys than girls, children with low gestational age or small-forgestational-age. ${ }^{46}$ Although NNSHs might be an intermediate or confounding factor in some of these associations, information about NNSHs was not available in the first EPIPAGE study. Thus, our study may provide a basis for future studies investigating the mechanisms that link NNSHs to related maxillofacial growth anomalies among preterm children.

\section{CONCLUSIONS}

This study has shown that in addition to factors associated with NNSHs among the general population (i.e., child sex, family sociodemographic characteristics and breast feeding), NNSHs in very preterm children were more frequent when children were fed by nasogastric at 36 weeks' CA and when children benefited from NIDCAP or Sensory-motor Development Care Programs in neonatal units. Although the practice of NNSHs largely depends on the maternal environment and family attitudes, more in-depth studies are needed to better understand the role of neonatal development care with respect to NNSHs and its possible impact on maxillofacial growth anomalies in preterm children. 


\section{ACKNOWLEDGEMENTS}

We are grateful to the families of preterm infants for their participation in the EPIPAGE-2 cohort study and for the cooperation of all maternity and neonatal units in France. We thank the EPIPAGE-2 Study Group for its substantial contribution to the conception, design, and acquisition of data. We would also like to acknowledge Laetitia Marchand-Martin and Dr Andrei S Morgan for their collaborative help in statistical methods. 


\section{REFERENCES}

1. Adair SM. Pacifier use in children: a review of recent literature. Pediatric Dentistry. 2003; 25:449-458.

2. Castilho SD, Rocha MAM. Pacifier habit: history and multidisciplinary view. Jornal de Pediatria. 2009; 85:480-489.

3. Levin S. History of Medicine: Dummies. South African Medical Journal. 1971; 237-240.

4. Sexton S, Natale R. Risks and benefits of pacifiers. American Family Physician. 2009; 79:681-685.

5. Zardetto CG del C, Rodrigues CRMD, Stefani FM. Effects of different pacifiers on the primary dentition and oral myofunctional structures of preschool children. Pediatric Dentistry. 2002; 24:552-560.

6. Warren JJ, Bishara SE. Duration of nutritive and non-nutritive sucking behaviors and their effects on the dental arches in the primary dentition. American Journal of Orthodontics Dentofacial Orthopedics. 2002; 121:347-356.

7. Adair SM, Milano M, Lorenzo I, Russell C. Effects of current and former pacifier use on the dentition of 24- to 59-month-old children. Pediatric Dentistry. 1995; 17:437-444.

8. Modéer T, Odenrick L, Lindner A. Sucking habits and their relation to posterior crossbite in 4-year-old children. Scandinavian Journal of Dental Research. 982; 90:323-328.

9. Duncan K, Mcnamara C, Ireland AJ, Sandy JR. Sucking habits in childhood and the effects on the primary dentition: findings of the Avon Longitudinal Study of Pregnancy and Childhood. International Journal of Paediatric Dentistry. 2008; 18:178-188.

10. North Stone K, Fleming P, Golding J. Socio-demographic associations with digit and pacifier sucking at 15 months of age and possible associations with infant infection. The ALSPAC Study Team. Avon Longitudinal Study of Pregnancy and Childhood. Early Human Development. 2000; 60:137-148.

11. Mauch CE, Scott JA, Magarey AM, Daniels LA. Predictors of and reasons for pacifier use in first-time mothers: an observational study. BMC Pediatrics. 2012; 12:7.

12. Maia-Nader M, Silva de Araujo Figueiredo $C$, Pinheiro de Figueiredo F, Moura da Silva $A A$, Thomaz EBAF, Saraiva MCP, et al. Factors associated with prolonged non-nutritive sucking habits in two cohorts of Brazilian children. BMC Public Health. 2014; 14:743.

13. Martins RFM, Lima A. SJ, Ribeiro CCC, Alves CMC, da Silva A. M, Thomaz EB a. F. Lower birthweight, shorter breastfeeding and lack of primary health care contributed to higher pacifier use in a birth cohort. Acta Paediatrica. 2018; 107:1650-1651.

14. Delaney AL, Arvedson JC. Development of swallowing and feeding: prenatal through first year of life. Developmental Disabilities Research Reviews. 2008; 14:105-117.

15. Miller JL, Sonies BC, Macedonia C. Emergence of oropharyngeal, laryngeal and 
swallowing activity in the developing fetal upper aerodigestive tract: an ultrasound evaluation. Early Human Development. 2003; 71:61-87.

16. Wambach K, Riordan J. Anatomy and Physiology of Lactation. In: Breastfeeding and Human Lactation. Burlington: Jones \& Bartlett Learning, Inc, 2016; pp.100-111.

17. McGrath JM, Braescu AVB. State of the science: feeding readiness in the preterm infant. The Journal of Perinatal \& Neonatal Nursing. 2004; 18:353-368; 369-370.

18. Bertoncelli N, Cuomo G, Cattani S, Mazzi C, Pugliese M, Coccolini E, et al. Oral Feeding Competences of Healthy Preterm Infants: A Review. International Journal of Pediatrics. 2012; 2012:1-5.

19. Nyqvist KH, Häggkvist A-P, Hansen MN, Kylberg E, Frandsen AL, Maastrup R, et al. Expansion of the baby-friendly hospital initiative ten steps to successful breastfeeding into neonatal intensive care: expert group recommendations. Journal of Human Lactation: Official Journal of International Lactation Consultant Association. 2013; 29:300-309.

20. Pinelli J, Symington A. Non-nutritive sucking for promoting physiologic stability and nutrition in preterm infants. The Cochrane Database Systematic Reviews. 2005; 4:CD001071.

21. Carbajal R, Chauvet X, Couderc S, Olivier-Martin M. Randomised trial of analgesic effects of sucrose, glucose, and pacifiers in term neonates. BMJ. 1999; 319:1393-1397.

22. Pillai Riddell RR, Racine NM, Gennis HG, Turcotte K, Uman LS, Horton RE, et al. Nonpharmacological management of infant and young child procedural pain. The Cochrane Database Systematic Reviews. 2015; 12:CD006275.

23. Ancel P-Y, Goffinet F. EPIPAGE 2 Writing Group. EPIPAGE 2: a preterm birth cohort in France in 2011. BMC Pediatrics. 2014; 14:97.

24. Ego A, Prunet C, Blondel B, Kaminski M, Goffinet F, Zeitlin J. [Customized and noncustomized French intrauterine growth curves. II - Comparison with existing curves and benefits of customization]. Journal de Gynécologie Obstétrique et Biologie de la Reproduction. 2016; 45:165-176.

25. Pierrat V, Coquelin A, Cuttini M, Khoshnood B, Glorieux I, Claris O, et al. Translating Neurodevelopmental Care Policies Into Practice: The Experience of Neonatal ICUs in France-The EPIPAGE-2 Cohort Study. Pediatric Critical Care Medicine. 2016; 17:957-967.

26. Westrup B. Family-Centered Developmentally Supportive Care. NeoReviews. 2014; 15:e325-335.

27. Ratynski N, Jouquan J, Sizun J. [Strategies for the NIDCAP implementation]. Archives de Pédiatrie: Organe Officiel De La Societe Francaise De Pediatrie. 2009; 16:830-832.

28. Als H, Lawhon G, Duffy FH, McAnulty GB, Gibes-Grossman R, Blickman JG. Individualized Developmental Care for the Very Low-Birth-Weight Preterm Infant: 
Medical and Neurofunctional Effects. JAMA. 1994; 272:853-858.

29. White IR, Royston P, Wood AM. Multiple imputation using chained equations: Issues and guidance for practice. Statistics in Medicine. 2011; 30:377-399.

30. Grund S, Robitzsch A, Luedtke O, Grund MS. (2018). Package 'mitml'. Retrieved from cran.r-project.org/web/packages/mitml/website. Accessed: July 10, 2019. [Google Scholar].

31. Buuren S van, Groothuis-Oudshoorn K. mice: Multivariate Imputation by Chained Equations in R. Journal of Statistical Software. 2011; 45:1-67

32. Rubin DB. Frontmatter. In Multiple Imputation for Nonresponse in Surveys. NY, New York: John Wiley \& Sons, Inc, 1987:i-xxix.

33. Halekoh U, Højsgaard S, Yan J. The R package geepack for generalized estimating equations. Journal of Statistical Software. 2006; 15:1-11.

34. Falissard B. Introduction to Data Manipulation Using R. In: Analysis of Questionnaire Data with R. New York: Taylor \& Francis group, LLC, 2012; pp. 223-247.

35. Ngom PI, Diagne F, Samba Diouf J, Ndiaye A, Hennequin M. [Prevalence and factors associated with non-nutritive sucking behavior. Cross sectional study among 5- to 6year-old Senegalese children]. Orthodontie Française. 2008; 79:99-106.

36. Chen X, Xia B, Ge L. Effects of breast-feeding duration, bottle-feeding duration and non-nutritive sucking habits on the occlusal characteristics of primary dentition. $B M C$ Pediatrics. 2015; 15:46.

37. Carcavalli L, Martins CC, Rocha IA, Parlato EM, Serra-Negra JM. Preterm Birth, Pacifier use and Breastfeeding: is there a Relationship? Brazilian Dental Journal. 2018; 29 4:388-394.

38. Lundqvist $\mathrm{C}$, Hafström M. Non-nutritive sucking in full-term and preterm infants studied at term conceptional age. Acta Paediatrica. 1999; 88:1287-1289.

39. Hepper PG, Shannon EA, Dornan JC. Sex differences in fetal mouth movements. The Lancet. 1997; 350:1820.

40. Miller JL, Macedonia C, Sonies B. Sex differences in prenatal oral-motor function and development. Developmental Medicine \& Child Neurology. 2007; 48:465-470.

41. Foster JP, Psaila K, Patterson T. Non-nutritive sucking for increasing physiologic stability and nutrition in preterm infants. The Cochrane Database Systematic Reviews. 2016; 10:CD001071.

42. Lubbe $W$, Ham-Baloyi $W$ ten. When is the use of pacifiers justifiable in the babyfriendly hospital initiative context? A clinician's guide. BMC Pregnancy Childbirth. 2017; 17:130.

43. Buccini G dos S, Benício MHD, Venancio SI. Determinants of using pacifier and bottle feeding. Revista de Saúde Pública. 2014; 48:571-82. 
44. Paulsson L, Bondemark L, Söderfeldt B. A systematic review of the consequences of premature birth on palatal morphology, dental occlusion, tooth-crown dimensions, and tooth maturity and eruption. The Angle Orthodontist. 2004; 74:269-279.

45. Larroque B. [EPIPAGE: epidemiologic study of very premature infants. Protocol of the survey]. Protocol of the survey. Archives de Pédiatrie. 2000; 7 (Suppl) 2:S339-S342.

46. Germa A, Marret S, Thiriez G, Rousseau S, Hascoët J-M, Paulsson-Björnsson L, et al. Neonatal factors associated with alteration of palatal morphology in very preterm children: the EPIPAGE cohort study. Early Human Development. 2012; 88:413-420.

47. Martinet $M$, Borradori Tolsa C, Rossi Jelidi M, Bullinger A, Perneger T, Pfister RE. [Development and assessment of a sensory-motor scale for the neonate: a clinical tool at the bedside]. Archives de Pediatrie : Organe Officiel de la Societe Francaise de Pediatrie. 2013; 20:137-145.

48. Jobe AH, Bancalari E. Bronchopulmonary dysplasia. American Journal of Respiratory Critical Care Medicine. 2001; 163:1723-1729.

49. Bell MJ, Ternberg JL, Feigin RD, Keating JP, Marshall R, Barton L, et al. Neonatal necrotizing enterocolitis. Therapeutic decisions based upon clinical staging. Annals of Surgery. 1978; 187:1-7.

50. International Committee for the Classification of Retinopathy of Prematurity. The International Classification of Retinopathy of Prematurity revisited. Archives of Ophthalmology. 2005; 123:991-999.

51. Volpe JJ. Brain injury in premature infants: a complex amalgam of destructive and developmental disturbances. The Lancet Neurology. 2009; 8:110-124. 


\section{FUNDING}

This project was funded by the following organizations: The French Institute of Public Health Research/Institute of Public Health and its partners: the French Health Ministry, the National Institute of Health and Medical Research (INSERM), the National Institute of Cancer, and the National Solidarity Fund for Autonomy (CNSA); The National Research Agency through the French EQUIPEX program of investments in the future (reference ANR-11-EQPX-0038); the PREMUP Foundation; and the Foundation de France (reference 00050329). The funders had no role in the study design, data collection and analysis, decision to publish, or preparation of the manuscript. 


\section{APPENDIX}

Note.1. Newborn Individualized Developmental Care and Assessment Program (NIDCAP) and Sensory-motor Development Care Programs. NIDCAP involves the observation of signs of stress during and after child caregiving procedures and proposes methods for adjusting care or the environment in an appropriate and supportive parental manner. ${ }^{26}$ The sensory-motor approach to development, which aims to stabilize the infant's sensoritonic balance by improving the environment and the quality of care, proposes sensorimotor experiences that assist in the maturation of the central nervous system, for example, by stimulating perioral and oral areas before meals with a cotton swab in a progressive manner based on a precise protocol so as to stimulate movement of the lips and the initiation of sucking activity. ${ }^{47}$

Note.2. Severe neonatal morbidities. The morbidities included any of the following conditions: 1) severe bronchopulmonary dysplasia (defined as administration of oxygen for at least 28 days plus the need for $\geq 30 \%$ oxygen and/or mechanical ventilatory support or continuous positive airway pressure at 36 weeks' postmenstrual age ${ }^{48} ; 2$ ) necrotising enterocolitis stage $2-3$ according to Bell et. al. ${ }^{49}$; 3) severe retinopathy of prematurity stage $>3$ according to the international classification ${ }^{50}$ and/or laser treatment; 4) any of the following severe cerebral abnormalities at cranial ultrasonography: intraventricular haemorrhage grade III or IV and intraparenchymal haemorrhage (i.e., large unilateral parenchymal hyperdensity or a large unilateral porencephalic cyst $)^{51}$ or cystic periventricular leukomalacia (i.e., periventricular white matter echolucency). 


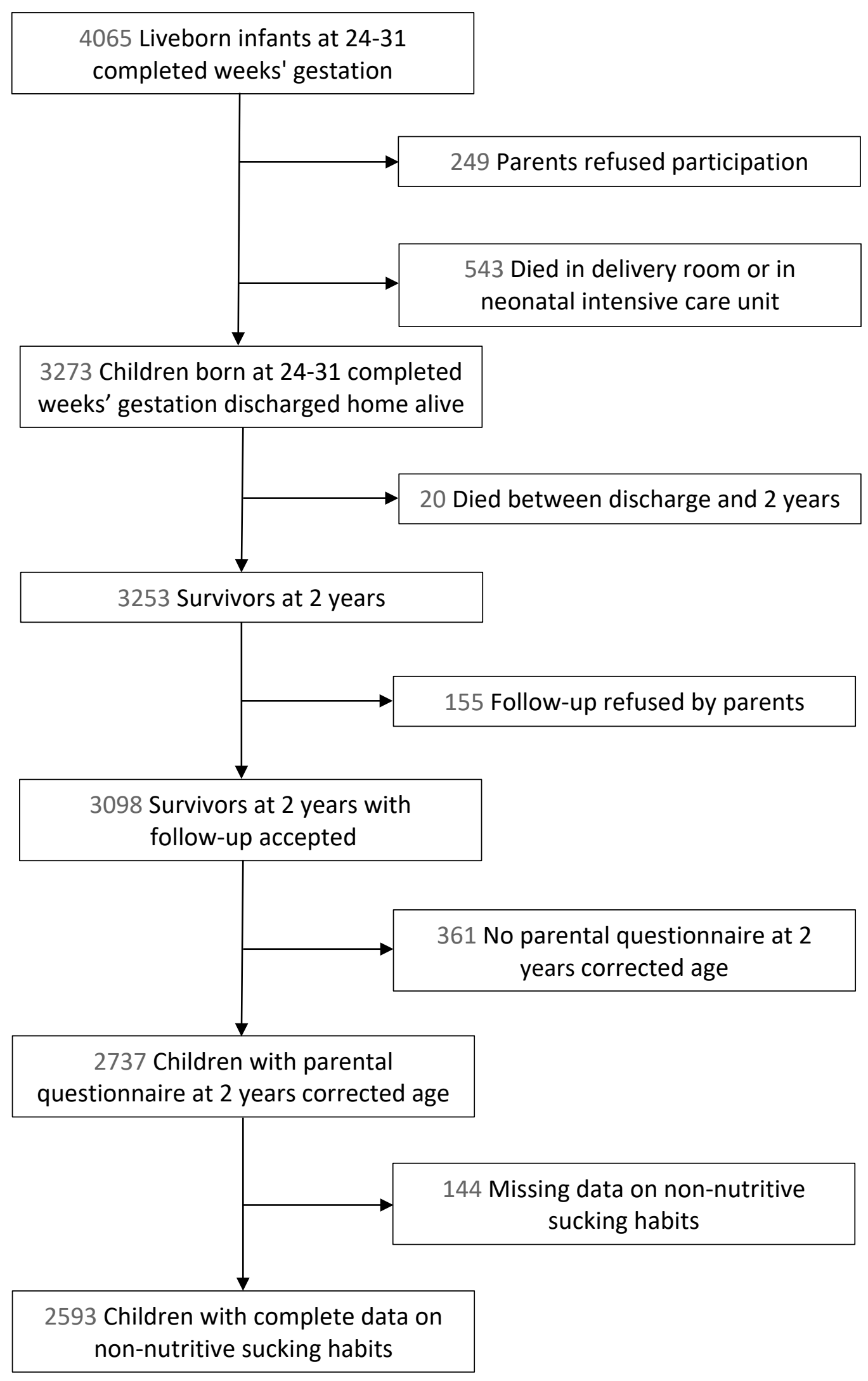


FIGURE 1 Flow chart of study population: EPIPAGE-2 cohort at 2 years' corrected age. 
TABLE 1 Sample description and non-nutritive sucking habits (NNSHs) at 2 years corrected age according to maternal and neonatal characteristics and care practices

\begin{tabular}{|c|c|c|c|c|}
\hline & \multirow[b]{2}{*}{$\mathrm{N}$} & \multirow[b]{2}{*}{$\%^{\mathrm{a}}$} & \multicolumn{2}{|c|}{ NNSHs } \\
\hline & & & $\mathrm{n}$ & $\%^{\mathrm{a}}$ \\
\hline Total & 2593 & 100 & 1800 & 69.4 \\
\hline \multicolumn{5}{|l|}{ Maternal characteristics } \\
\hline \multicolumn{5}{|l|}{ Maternal age (years) } \\
\hline$<25$ & 401 & 15.5 & 266 & 66.4 \\
\hline $25-34$ & 1603 & 61.7 & 1137 & 70.9 \\
\hline$\geq 35$ & 589 & 22.8 & 397 & 67.4 \\
\hline \multicolumn{5}{|l|}{ Country of birth } \\
\hline France & 2021 & 78.4 & 1502 & 74.4 \\
\hline Other & 562 & 21.6 & 292 & 51.5 \\
\hline \multicolumn{5}{|l|}{ Parity } \\
\hline 0 & 1447 & 56.1 & 1038 & 71.8 \\
\hline 1 & 600 & 23.5 & 433 & 72.1 \\
\hline$\geq 2$ & 524 & 20.4 & 314 & 59.7 \\
\hline \multicolumn{5}{|l|}{ Type of pregnancy } \\
\hline Single & 1731 & 66.7 & 1166 & 67.3 \\
\hline Multiple & 862 & 33.3 & 634 & 73.6 \\
\hline \multicolumn{5}{|l|}{ Parents' socioeconomic status ${ }^{\mathrm{b}}$} \\
\hline Professional & 585 & 23.4 & 410 & 70.3 \\
\hline Intermediate & 559 & 22.7 & 425 & 75.9 \\
\hline $\begin{array}{r}\text { Administrative, public service, self-employed, } \\
\text { students }\end{array}$ & 665 & 27.0 & 464 & 69.8 \\
\hline Shop assistants, service workers & 343 & 13.6 & 227 & 66.3 \\
\hline Manual workers & 271 & 11.0 & 173 & 62.8 \\
\hline Unknown & 60 & 2.3 & 31 & 52.2 \\
\hline \multicolumn{5}{|l|}{ Neonatal characteristics } \\
\hline \multicolumn{5}{|l|}{ Sex } \\
\hline Boys & 1345 & 52.0 & 887 & 65.9 \\
\hline Girls & 1248 & 48.0 & 913 & 73.2 \\
\hline \multicolumn{5}{|l|}{ Gestational age (weeks) } \\
\hline $24-26$ & 422 & 12.6 & 294 & 69.7 \\
\hline $27-31$ & 2171 & 87.4 & 1506 & 69.4 \\
\hline \multicolumn{5}{|l|}{ Small-for-gestational-age ${ }^{c}$} \\
\hline No & 1684 & 64.3 & 1147 & 68.1 \\
\hline Yes & 909 & 35.7 & 653 & 71.7 \\
\hline \multicolumn{5}{|l|}{ Health status during hospitalization } \\
\hline \multicolumn{5}{|l|}{ Severe neonatal morbidities ${ }^{d}$} \\
\hline No & 2070 & 84.8 & 1412 & 68.2 \\
\hline Yes & 400 & 15.2 & 295 & 74.2 \\
\hline \multicolumn{5}{|l|}{$\begin{array}{l}\text { Feeding by nasogastric tube at } 36 \text { weeks' } \\
\text { corrected age }\end{array}$} \\
\hline No & 787 & 34.9 & 513 & 65.1 \\
\hline Yes & 1529 & 65.1 & 1090 & 71.4 \\
\hline
\end{tabular}


Developmental care practices

NIDCAPe or Sensory-motor Developmental Care

Programs

$$
\begin{array}{ccccc}
\text { No } & 2270 & 90.1 & 1559 & 68.7 \\
\text { Yes } & 253 & 9.9 & 194 & 76.6
\end{array}
$$

Oral stimulation

$$
\begin{array}{ccccc}
\text { No } & 718 & 29.4 & 498 & 69.5 \\
\text { Yes } & 1736 & 70.6 & 1203 & 69.2
\end{array}
$$

Breast feeding at discharge

$$
\begin{array}{ccccc}
\text { No } & 1503 & 60.6 & 1093 & 72.9 \\
\text { Yes } & 965 & 39.4 & 622 & 64.2
\end{array}
$$

aPercentages weighted to account for differences in the sampling process between gestational age groups.

${ }^{\mathrm{b}}$ Defined as the highest occupational status of the mother and father or occupation of mother only if living alone.

'Defined as birth weight less than the 10th centile for gestational age and sex based on the French EPOPé intrauterine growth curves (Ego 2016).

${ }^{d}$ Severe neonatal morbidity was defined as severe bronchopulmonary dysplasia or necrotising enterocolitis stage 2-3 or severe retinopathy of prematurity stage $>3$ or any of the following severe cerebral abnormalities on cranial ultrasonography: intraventricular haemorrhage grade III/IV or cystic periventricular leukomalacia. eNIDCAP, Newborn Individualized Developmental Care Program. 
TABLE 2 Non-nutritive sucking habits (NNSHs) at 2 years corrected age according to maternal and neonatal characteristics and care practices: unadjusted and adjusted Risk Ratios (RRs), multivariable log-linear regression models with generalized estimating equations (GEE) with multiple imputation ( $N=3253$ )

\begin{tabular}{|c|c|c|c|c|}
\hline & $\begin{array}{l}\text { Unadjusted } \\
\operatorname{RR}(95 \% \mathrm{Cl})^{\mathrm{a}}\end{array}$ & $\begin{array}{c}\text { Model } 1 \\
\operatorname{aRR}(95 \% \mathrm{Cl})^{\mathrm{b}}\end{array}$ & $\begin{array}{c}\text { Model } 2 \\
\operatorname{aRR}(95 \% \mathrm{CI})^{\mathrm{c}}\end{array}$ & $\begin{array}{c}\text { Model } 3 \\
\operatorname{aRR}(95 \% \mathrm{CI})^{d}\end{array}$ \\
\hline \multicolumn{5}{|l|}{ Maternal age (years) } \\
\hline$<25$ & $0.93(0.87,0.99)$ & $0.96(0.88,1.03)$ & & \\
\hline $25-34$ & 1.00 (Reference) & 1.00 (Reference) & & \\
\hline$\geq 35$ & $0.96(0.91,1.02)$ & $1.01(0.94,1.07)$ & & \\
\hline \multicolumn{5}{|l|}{ Maternal country of birth } \\
\hline France & 1.00 (Reference) & 1.00 (Reference) & & \\
\hline Other & $0.67(0.62,0.72)$ & $0.70(0.64,0.77)$ & & \\
\hline \multicolumn{5}{|l|}{ Parity } \\
\hline 0 & 1.00 (Reference) & 1.00 (Reference) & & \\
\hline 1 & $1.00(0.96,1.06)$ & $1.02(0.96,1.08)$ & & \\
\hline$\geq 2$ & $0.89(0.83,0.94)$ & $0.88(0.82,0.96)$ & & \\
\hline \multicolumn{5}{|l|}{ Type of pregnancy } \\
\hline Single & 1.00 (Reference) & 1.00 (Reference) & & \\
\hline Multiple & $1.07(1.01,1.11)$ & $1.07(1.00,1.11)$ & & \\
\hline \multicolumn{5}{|l|}{ Parents' socioeconomic status ${ }^{\mathrm{e}}$} \\
\hline Professional & $0.93(0.87,1.00)$ & $0.93(0.86,1.00)$ & & \\
\hline Intermediate & 1.00 (Reference) & 1.00 (Reference) & & \\
\hline $\begin{array}{r}\text { Administrative, public service, self- } \\
\text { employed, students }\end{array}$ & $0.91(0.86,0.97)$ & $0.96(0.90,1.03)$ & & \\
\hline Shop assistants, service workers & $0.89(0.82,0.96)$ & $0.94(0.86,1.02)$ & & \\
\hline Manual workers & $0.87(0.80,0.95)$ & $0.95(0.86,1.05)$ & & \\
\hline Unknown & $0.66(0.55,0.79)$ & $0.78(0.63,0.98)$ & & \\
\hline \multicolumn{5}{|l|}{ Sex } \\
\hline Boys & 1.00 (Reference) & 1.00 (Reference) & & \\
\hline Girls & $1.10(1.05,1.16)$ & $1.12(1.05,1.17)$ & & \\
\hline \multicolumn{5}{|l|}{ Gestational age (weeks) } \\
\hline $24-26$ & $1.02(0.95,1.08)$ & & $1.02(0.96,1.09)$ & \\
\hline $27-31$ & 1.00 (Reference) & & 1.00 (Reference) & \\
\hline \multicolumn{5}{|l|}{ Small-for-gestational age ${ }^{f}$} \\
\hline No & 1.00 (Reference) & & 1.00 (Reference) & \\
\hline $\begin{array}{rr}\text { Yes }\end{array}$ & $1.05(0.92,1.06)$ & & $1.06(0.99,1.12)$ & \\
\hline \multicolumn{5}{|l|}{$\begin{array}{l}\text { Feeding by nasogastric tube at } 36 \\
\text { weeks' corrected age }\end{array}$} \\
\hline No & 1.00 (Reference) & & & 1.00 (Reference) \\
\hline Yes & $1.10(1.04,1.15)$ & & & $1.07(1.01,1.13)$ \\
\hline \multicolumn{5}{|l|}{ NIDCAPg or Sensory-motor } \\
\hline \multicolumn{5}{|l|}{ Developmental Care Programs } \\
\hline No & 1.00 (Reference) & & & 1.00 (Reference) \\
\hline Yes & $1.17(1.09,1.23)$ & & & $1.10(1.02,1.19)$ \\
\hline \multicolumn{5}{|l|}{ Oral stimulation } \\
\hline No & 1.00 (Reference) & & & 1.00 (Reference) \\
\hline Yes & $0.98(0.96,1.06)$ & & & $0.98(0.93,1.04)$ \\
\hline \multicolumn{5}{|l|}{ Breast feeding at discharge } \\
\hline No & 1.00 (Reference) & & & 1.00 (Reference) \\
\hline Yes & $0.90(0.86,0.95)$ & & & $0.90(0.85,0.95)$ \\
\hline \multicolumn{5}{|c|}{$\begin{array}{l}\text { aUnadjusted RRs weighted to account for differences in the sampling process between gestational age groups. } \\
\text { baRR, adjusted RRs; } 95 \% \mathrm{Cl}, 95 \% \text { confidence interval; adjusted for maternal age, maternal country of birth, parity, } \\
\text { type of pregnancy, parents' socioeconomic status and child sex, GEE multivariable log-linear regression model. } \\
\text { caRRs; } 95 \% \mathrm{Cl} \text {; adjusted for maternal age, maternal country of birth, parity, type of pregnancy, parents' } \\
\text { socioeconomic status, child sex, gestational age and small-for-gestational-age, GEE multivariable log-linear } \\
\text { regression model. }\end{array}$} \\
\hline
\end{tabular}


fDefined as birth weight less than the 10th centile for gestational age and sex based on French EPOPé intrauterine growth curves (Ego 2016).

gNIDCAP, Newborn Individualized Developmental Care Program. 
eFigure 1 Directed Acyclic Graph (DAG) of factors associated with non-nutritive sucking habits at 2 years of age

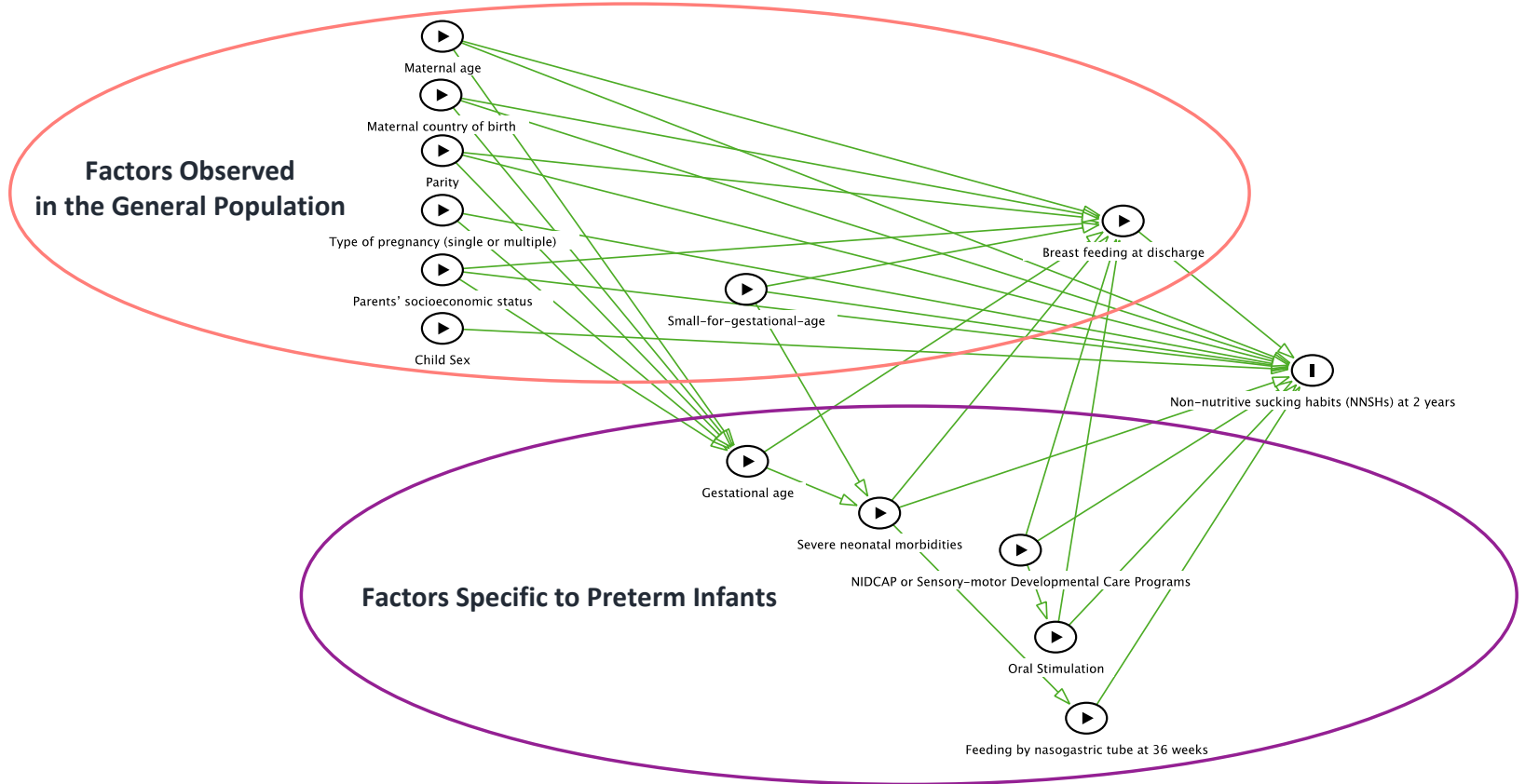

DAG created with the web-based application: www.dagitty.net 
efigure 1 Directed Acyclic Graph (DAG) of factors associated with non-nutritive sucking habits at 2 years of age among very preterm children. 
eTable 1 Type of variable, model used to predict missing data, and percentages of values missing for each variable included in the imputation model ( $N=3253$ survivors at 2 years' corrected age)

\begin{tabular}{|c|c|c|c|}
\hline Variable & $\begin{array}{l}\text { Type of } \\
\text { variable }\end{array}$ & $\begin{array}{l}\text { Model used to } \\
\text { predict missing } \\
\text { data }\end{array}$ & $\begin{array}{l}\text { Percentages of } \\
\text { values missing }\end{array}$ \\
\hline Non-nutritive sucking habits (NNSHs) & Binary & $\begin{array}{l}\text { Logistic } \\
\text { regression }\end{array}$ & $20 \%$ \\
\hline Maternal age (years) & $\begin{array}{l}\text { Categorical } \\
\text { (3 categories) }\end{array}$ & $\begin{array}{l}\text { Multinomial } \\
\text { regression }\end{array}$ & $<1 \%$ \\
\hline Maternal country of birth & Binary & $\begin{array}{l}\text { Logistic } \\
\text { regression }\end{array}$ & $17 \%$ \\
\hline Parity & $\begin{array}{l}\text { Categorical } \\
\text { (3 categories) }\end{array}$ & $\begin{array}{l}\text { Multinomial } \\
\text { regression }\end{array}$ & $1 \%$ \\
\hline Type of pregnancy & Binary & No missing data & $0 \%$ \\
\hline Parents' socioeconomic status ${ }^{a}$ & $\begin{array}{l}\text { Categorical } \\
\text { (6 categories) }\end{array}$ & $\begin{array}{l}\text { Multinomial } \\
\text { regression }\end{array}$ & $5 \%$ \\
\hline Sex & Binary & No missing data & $0 \%$ \\
\hline Gestational age (weeks) & Binary & No missing data & $0 \%$ \\
\hline Small-for-gestational-age ${ }^{b}$ & Binary & No missing data & $0 \%$ \\
\hline $\begin{array}{l}\text { Feeding by nasogastric tube at } 36 \text { weeks' } \\
\text { corrected age }\end{array}$ & Binary & $\begin{array}{l}\text { Logistic } \\
\text { regression }\end{array}$ & $11 \%$ \\
\hline $\begin{array}{l}\text { NIDCAPC or Sensory-motor Developmental Care } \\
\text { Programs }\end{array}$ & Binary & $\begin{array}{l}\text { Logistic } \\
\text { regression }\end{array}$ & $3 \%$ \\
\hline Oral stimulation & Binary & $\begin{array}{l}\text { Logistic } \\
\text { regression }\end{array}$ & $6 \%$ \\
\hline Breast feeding at discharge & Binary & $\begin{array}{l}\text { Logistic } \\
\text { regression }\end{array}$ & $5 \%$ \\
\hline
\end{tabular}


eTable 2 Maternal, social and neonatal characteristics of the study population, children lost to follow-up and those with missing data on the outcome

\begin{tabular}{|c|c|c|c|c|c|c|}
\hline & \multicolumn{2}{|c|}{$\begin{array}{c}\text { Study } \\
\text { Population }\end{array}$} & \multicolumn{2}{|c|}{$\begin{array}{l}\text { Lost to } \\
\text { follow-up }\end{array}$} & \multicolumn{2}{|c|}{ Missing data } \\
\hline & $\mathrm{N}$ & $\%^{a}$ & $\mathrm{n}$ & $\%^{a}$ & $\mathrm{n}$ & $\%^{a}$ \\
\hline Total & 2593 & 100 & 516 & 100 & 144 & 100 \\
\hline \multicolumn{7}{|l|}{ Maternal characteristics } \\
\hline \multicolumn{7}{|l|}{ Maternal age (years) } \\
\hline$<25$ & 401 & 15.5 & 177 & 34.1 & 34 & 23.5 \\
\hline $25-34$ & 1603 & 61.7 & 248 & 48.2 & 70 & 49.5 \\
\hline$\geq 35$ & 589 & 22.8 & 91 & 17.7 & 39 & 27.0 \\
\hline \multicolumn{7}{|l|}{ Maternal country of birth } \\
\hline France & 2021 & 78.4 & 364 & 73.6 & 70 & 49.2 \\
\hline Other & 562 & 21.6 & 129 & 26.4 & 71 & 50.8 \\
\hline \multicolumn{7}{|l|}{ Parity } \\
\hline 0 & 1447 & 56.1 & 224 & 44.6 & 75 & 53.1 \\
\hline 1 & 600 & 23.5 & 121 & 23.8 & 39 & 26.8 \\
\hline$\geq 2$ & 524 & 20.4 & 158 & 31.6 & 29 & 20.1 \\
\hline \multicolumn{7}{|l|}{ Type of pregnancy } \\
\hline Single & 1731 & 66.7 & 376 & 73.2 & 92 & 63.2 \\
\hline Multiple & 862 & 33.3 & 140 & 26.8 & 52 & 36.8 \\
\hline \multicolumn{7}{|l|}{ Parents' socioeconomic status ${ }^{b}$} \\
\hline Professional & 585 & 23.4 & 41 & 9.1 & 30 & 21.5 \\
\hline Intermediate & 559 & 22.7 & 58 & 13.0 & 14 & 10.3 \\
\hline $\begin{array}{r}\text { Administrative, public service, self-employed, } \\
\text { students }\end{array}$ & 665 & 27.0 & 134 & 29.8 & 40 & 28.7 \\
\hline Shop assistants, service workers & 343 & 13.6 & 83 & 18.5 & 23 & 16.8 \\
\hline Manual workers & 271 & 11.0 & 91 & 19.5 & 28 & 20.5 \\
\hline Unknown & 60 & 2.3 & 46 & 10.1 & 3 & 2.2 \\
\hline
\end{tabular}

Neonatal characteristics

Sex

Gestational age (weeks)

$\begin{array}{lllllll}\text { Boys } & 1345 & 52.0 & 270 & 52.3 & 83 & 57.4 \\ \text { Girls } & 1248 & 48.0 & 246 & 47.7 & 61 & 42.6\end{array}$

Small-for-gestational-age ${ }^{c}$

$\begin{array}{ccccccc}24-26 & 422 & 12.6 & 98 & 14.8 & 24 & 12.9 \\ 27-31 & 2171 & 87.4 & 418 & 85.2 & 120 & 87.1\end{array}$

Health status during hospitalization

$\begin{array}{ccccccc}\text { No } & 1684 & 64.3 & 342 & 65.4 & 93 & 63.7 \\ \text { Yes } & 909 & 35.7 & 174 & 34.6 & 51 & 36.3\end{array}$

Severe neonatal morbidities ${ }^{d}$

$\begin{array}{rcccccc}\text { No } & 2070 & 84.8 & 393 & 82.9 & 117 & 85.3 \\ \text { Yes } & 400 & 15.2 & 88 & 17.1 & 21 & 14.7\end{array}$

Feeding by nasogastric tube at 36 weeks' corrected age

$\begin{array}{ccccccc}\text { No } & 787 & 34.9 & 178 & 42.7 & 54 & 41.5 \\ \text { Yes } & 1529 & 65.1 & 251 & 57.3 & 79 & 58.5\end{array}$


Developmental care practices

NIDCAPe or Sensory-motor Developmental Care

Programs

No $2270 \quad 90.1 \quad 426 \quad 87.5 \quad 132 \quad 93.0$

Oral stimulation

$\begin{array}{lllllll}\text { Yes } & 253 & 9.9 & 62 & 12.5 & 10 & 7.0\end{array}$

$\begin{array}{lllllll}\text { No } & 718 & 29.4 & 143 & 31.7 & 47 & 33.5\end{array}$

$\begin{array}{lllllll}\text { Yes } & 1736 & 70.6 & 317 & 68.3 & 93 & 66.5\end{array}$

Breast feeding at discharge

$\begin{array}{lllllll}\text { No } & 1503 & 60.6 & 349 & 73.1 & 89 & 65.0\end{array}$

$\begin{array}{lllllll}\text { Yes } & 965 & 39.4 & 126 & 26.9 & 47 & 35.0\end{array}$

aPercentages weighted to account for differences in the sampling process between gestational age groups.

${ }^{b}$ Defined as the highest occupational status of the mother and father or occupation of mother only if living alone.

'Defined as birth weight less than the 10th centile for gestational age and sex based on French EPOPé intrauterine growth curves (Ego 2016).

dSevere neonatal morbidity was defined as severe bronchopulmonary dysplasia or necrotising enterocolitis stage 2-3, severe retinopathy of prematurity stage $>3$ or any of the following severe cerebral abnormalities on cranial ultrasonography: intraventricular haemorrhage grade III/IV or cystic periventricular leukomalacia.

eNIDCAP, Newborn Individualized Developmental Care Program. 
eTable 3 Non-nutritive sucking habits (NNSHs) at 2 years corrected age according to maternal and neonatal characteristics and care practices: multivariable log-linear regression models with generalized estimating equations (GEE)

\begin{tabular}{|c|c|c|}
\hline & $\begin{array}{l}\text { Multiple Imputation } \\
\qquad \mathrm{N}=3253\end{array}$ & $\begin{array}{l}\text { Complete Cases } \\
\qquad \mathrm{N}=1863\end{array}$ \\
\hline & $\operatorname{aRR}(95 \% \mathrm{Cl})^{\mathrm{a}}$ & $\operatorname{aRR}(95 \% \mathrm{Cl})^{\mathrm{a}}$ \\
\hline \multicolumn{3}{|l|}{ Maternal age (years) } \\
\hline$<25$ & $0.95(0.89,1.02)$ & $0.98(0.89,1.08)$ \\
\hline $25-34$ & 1.00 (Reference) & 1.00 (Reference) \\
\hline$\geq 35$ & $1.00(0.94,1.07)$ & $1.01(0.93,1.09)$ \\
\hline \multicolumn{3}{|l|}{ Maternal country of birth } \\
\hline France & 1.00 (Reference) & 1.00 (Reference) \\
\hline Other & $0.72(0.65,0.78)$ & $0.75(0.68,0.82)$ \\
\hline \multicolumn{3}{|l|}{ Parity } \\
\hline 0 & 1.00 (Reference) & 1.00 (Reference) \\
\hline 1 & $1.03(0.97,1.09)$ & $1.08(1.01,1.16)$ \\
\hline$\geq 2$ & $0.88(0.82,0.96)$ & $0.90(0.81,0.99)$ \\
\hline \multicolumn{3}{|l|}{ Type of pregnancy } \\
\hline Single & 1.00 (Reference) & 1.00 (Reference) \\
\hline Multiple & $1.06(1.00,1.11)$ & $1.09(1.02,1.17)$ \\
\hline \multicolumn{3}{|l|}{ Parents' socioeconomic status ${ }^{b}$} \\
\hline Professional & $0.94(0.88,1.01)$ & $0.94(0.87,1.03)$ \\
\hline Intermediate & 1.00 (Reference) & 1.00 (Reference) \\
\hline $\begin{array}{r}\text { Administrative, public service, self-employed, } \\
\text { students }\end{array}$ & $0.95(0.89,1.02)$ & $0.93(0.85,1.01)$ \\
\hline Shop assistants, service workers & $0.92(0.85,1.01)$ & $0.94(0.85,1.05)$ \\
\hline Manual workers & $0.94(0.85,1.03)$ & $0.89(0.79,1.01)$ \\
\hline Unknown & $0.78(0.62,0.97)$ & $0.74(0.53,1.03)$ \\
\hline \multicolumn{3}{|l|}{ Sex } \\
\hline Boys & 1.00 (Reference) & 1.00 (Reference) \\
\hline Girls & $1.11(1.06,1.17)$ & $1.08(1.02,1.15)$ \\
\hline \multicolumn{3}{|l|}{ Gestational age (weeks) } \\
\hline $24-26$ & $0.99(0.93,1.06)$ & $1.00(0.92,1.09)$ \\
\hline $27-31$ & 1.00 (Reference) & 1.00 (Reference) \\
\hline \multicolumn{3}{|l|}{ Small-for-gestational-age ${ }^{c}$} \\
\hline 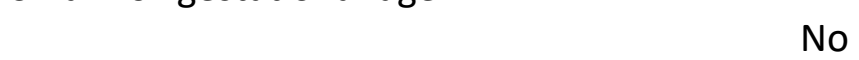 & 1.00 (Reference) & 1.00 (Reference) \\
\hline Yes & $1.04(0.99,1.10)$ & $1.04(0.97,1.10)$ \\
\hline \multicolumn{3}{|l|}{$\begin{array}{l}\text { Feeding by nasogastric tube at } 36 \text { weeks' } \\
\text { corrected age }\end{array}$} \\
\hline No & 1.00 (Reference) & 1.00 (Reference) \\
\hline Yes & $1.07(1.01,1.13)$ & $1.06(0.99,1.13)$ \\
\hline \multicolumn{3}{|l|}{$\begin{array}{l}\text { NIDCAPd or Sensory-motor Developmental Care } \\
\text { Programs }\end{array}$} \\
\hline No & 1.00 (Reference) & 1.00 (Reference) \\
\hline Yes & $1.10(1.02,1.19)$ & $1.10(1.02,1.20)$ \\
\hline \multicolumn{3}{|l|}{ Oral stimulation } \\
\hline No & 1.00 (Reference) & 1.00 (Reference) \\
\hline
\end{tabular}


Breast feeding at discharge

$\begin{array}{lll}\text { No } & 1.00 \text { (Reference) } & 1.00 \text { (Reference) } \\ \text { Yes } & 0.90(0.85,0.95) & 0.90(0.85,0.97)\end{array}$

aaRR, adjusted Risk Ratio; $95 \% \mathrm{Cl}, 95 \%$ confidence interval; adjusted for all variables in the table, GEE multivariable log-linear regression models.

${ }^{b}$ Defined as the highest occupational status of the mother and father or occupation of mother only if living alone.

'Defined as birth weight less than the 10th centile for gestational age and sex based on the French EPOPé intrauterine growth curves (Ego 2016).

${ }^{\mathrm{d}}$ NIDCAP, Newborn Individualized Developmental Care Program. 